\title{
Efficiency and boiler parameters effects in sub-critical boiler with different types of sub- bituminous coal
}

\begin{abstract}
It has been a practice for almost all countries to run coal-fired power plant as a base load supplying the electricity. Coal is selected as main fuel as the coal price remains lower as compared to dry natural gas, medium fuel oil and distillate. Boiler as the main device in power generation must be capable and reliable in ensuring the steam production is continuous without any disruption. During the commissioning stage, boiler operation will be designed and tuned as per coal specification considering the environmental factor. However, the source of available coal used during commissioning is limited and alternative coal must be found. Coal with different characteristic will affect the boiler performance and parameters. From this study, the results indicate that coal with different calorific value $(\mathrm{CV})$ and properties gives different efficiency to the boiler. The results show that the sub-bituminous coal with $\mathrm{CV} 5013 \mathrm{kcal} / \mathrm{kg}$ performs similarly to designate coal with CV $4852 \mathrm{kcal} / \mathrm{kg}$. Besides that, the superheated steam and reheater steam for coal CV $5013 \mathrm{kcal} / \mathrm{kg}$ perform at normal value which is close to $540{ }^{\circ} \mathrm{C}$ setting point. The desuperheater spray water flows operate between 18 and $25 \mathrm{t} / \mathrm{h}$ with minimal operation to achieve the target value, $540{ }^{\circ} \mathrm{C}$.
\end{abstract}

